\title{
Effects of elastic foundation on the vibration of laminated non-homogeneous orthotropic circular cylindrical shells
}

\author{
A.H. Sofiyev ${ }^{\mathrm{a}, *}$, S.N. Keskin ${ }^{\mathrm{a}}$ and Ali H. Sofiyev ${ }^{\mathrm{b}}$ \\ ${ }^{a}$ Department of Civil Engineering of Suleyman Demirel University, Isparta, Turkey \\ ${ }^{\mathrm{b}}$ Technical Sciences Department of Kasakh Branch of Azerbaijan Teachers Institute, Kazakh, Azerbaijan
}

\begin{abstract}
In this paper an analytical procedure is given to study the free vibration characteristics of laminated non-homogeneous orthotropic thin circular cylindrical shells resting on elastic foundation, accounting for Karman type geometric non-linearity. At first, the basic relations and modified Donnell type stability equations, considering finite deformations, have been obtained for laminated thin orthotropic circular cylindrical shells, the Young's moduli of which varies piecewise continuously in the thickness direction. Applying Galerkin method to the latter equations, a non-linear time dependent differential equation is obtained for the displacement amplitude. The frequency is obtained from this equation as a function of the shell displacement amplitude. Finally, the effect of elastic foundation, non-linearity, non-homogeneity, the number and ordering of layers on the frequency is found for different mode numbers. These results are given in the form of tables and figures. The present analysis is validated by comparing results with those in the literature.
\end{abstract}

Keywords: Elastic foundation, vibration, natural and nonlinear frequencies, cross-ply laminated cylindrical shells, orthotropic material

\section{Introduction}

Multi-layered composite shells composed of nonhomogeneous materials with different elastic properties are being used extensively as structural elements in modern construction engineering, ship building, nuclear, space and aeronautical industries as well as the petroleum and petrochemical industries (pressure vessel, pipeline). These materials have properties that vary as a function of position in the body. Nonhomogeneous materials can frequently be found in nature as well as in man-made structures. However, typically non-homogeneous materials seem to be those with elastic constants varying continuously in different spa-

*Corresponding author: Assoc. Prof. Dr. Abdullah Sofiyev, Department of Civil Engineering of Suleyman Demirel, University, Isparta, Turkey. Tel: +90 246 2111243; Fax: +90 2462370859 ; E-mail: asofiyev@mmf.sdu.edu.tr. tial directions. Continuous non-homogeneity is a direct generalization of homogeneity in theory; besides, material non-homogeneity becomes essential and must sufficiently be considered in a number of practical situations. In all the referenced works, and in most of available solutions to elastic non-homogeneity, it is assumed that the material is isotropic or orthotropic, the Poisson's ratio is constant, and the Young's moduli is either an exponential or a power function of a spatial variable [5,8,12-14,28,32]. Cylindrical shells made of different materials that have continuous and thorough contact with an elastic medium, solid or liquid, either on an outer or inner surface is considered as cylindrical shells on an elastic foundation. Such components and structures are often subjected to dynamic loads. Flowinduced vibrations in heat exchangers and pipelines, wave loading on submarines, vibrations of fuel-filled drop tanks of fighter aircraft, underground and undersea pipelines, and tunnels and semicircular roofs of underground aircraft hangers subject to seismic forces, 
nuclear explosions, and other blasts are some of the numerous examples.

Significant contributions have been made in the field of non-linear vibrations of cylindrical shells in general. Some of these studies about this subject are given $[9,15$, $20,22,23,25,26,31,37]$. Linear and non-linear free vibrations of laminated plates and shells have been studied only recently see [1-3,6,7,19,27,29,30,33,36,39]. However, vibrations of shells on elastic foundations have been studied only recently see [4,11,16-18,21,35, $38,40]$. In most of these studies, the authors investigate the vibrations of an orthotropic cylindrical shell on an elastic foundation using membrane theory. It is known that, response of elastic media can be presented by using Winkler and Pasternak foundation models. In this study, response of elastic media is given by Winkler foundation model. It is known that Winkler represented an elastic foundation by a set of closely spaced, independent linear springs.

The effect of all three factors together that nonhomogeneity, geometric non-linearity and elastic foundation to the vibration modes of laminated shells are not studied enough. In this study, vibration problem in large deformations of laminated non-homogeneous orthotropic cylindrical shells resting on an elastic foundation is taken up and the effect of all three factors together in question to the vibration frequency is researched.

\section{Formulation of the problem}

Consider a thin circular cylindrical shell as shown in Fig. 1, composed of $\mathrm{N}$ layers of equal thickness of nonhomogeneous orthotropic composite material perfectly bonded together. The shell is on elastic foundation and of length $\mathrm{L}$, total thickness $2 \mathrm{~h}$ and radius $\mathrm{R}$. In Fig. 1 , the $x$ and $y$ axes are in the middle plane of the shell in the axial and tangential directions, respectively, and the $z$ axis normal to them. The axes of orthotropy in all layers are parallel to $x$ and $y$ axes.

The equations of motion of circular cylindrical thin shells resting on an elastic foundation are as follows [10,38]:

$$
\begin{aligned}
& N_{11, x}+N_{12, y}=\rho_{1} h_{1} u_{, t t} \\
& N_{21, x}+N_{22, y}=\rho_{1} h_{1} v_{, t t} \\
& M_{11, x x}+2 M_{12, x y}+M_{22, y y}+N_{22} / R \\
& +N_{11} w_{, x x}+2 N_{12} w_{, x y}+N_{22} w_{, y y}-k_{0} w \\
& =\rho_{1} h_{1} w_{, t t}
\end{aligned}
$$

where $h_{1}=2 h$, a comma denotes partial differentiation with respect to the corresponding coordinates, $N_{11}, N_{22}$ and $N_{12}$ are, respectively, the axial and circumferential normal forces and the accompanying shear force; $M_{11}, M_{22}$ and $M_{12}$ are, respectively, the bending moments in axial and circumferential directions and the accompanying twisting moment, $u, v$ and $w$ are, respectively, the displacements on the reference surface in the directions of $x, y$ and $z$ axes, $t$ is time coordinate, $k_{0}$ is foundation modulus and the following definitions apply:

$$
\rho_{1}=\sum_{k=1}^{N} \rho_{0}^{(k)} / N
$$

in which $\rho_{0}^{(k)}$ are the densities of the homogeneous materials, in the kth layer.

The Kirchhoff hypothesis on non-deformable normal element and Karman type geometric non-linearity are taken into account. In that case, in large deformation the stress-strain relations for a thin laminated layer, which has non-uniform Young's moduli with respect to the thickness coordinate, are given as follows

$$
\begin{aligned}
& \left(\begin{array}{l}
\sigma_{11}^{(k)} \\
\sigma_{22}^{(k)} \\
\sigma_{12}^{(k)}
\end{array}\right)=\left[\begin{array}{lll}
Q_{11}^{(k)} & Q_{12}^{(k)} & 0 \\
Q_{12}^{(k)} & Q_{22}^{(k)} & 0 \\
0 & 0 & Q_{66}^{(k)}
\end{array}\right] \\
& {\left[\begin{array}{l}
u_{, x}+0.5\left(w_{, x}\right)^{2}-z w_{, x x} \\
v_{, y}-w / R+0.5\left(w_{, y}\right)^{2}-z w_{, y y} \\
0.5\left(u, y+v_{, x}\right)+w_{, x} w_{, y}-z w_{, x y}
\end{array}\right]}
\end{aligned}
$$

where $\sigma_{11}^{(k)}, \sigma_{22}^{(k)}$ and $\sigma_{12}^{(k)}$ are the stresses in the layers. The quantities $Q_{i j}^{(k)}, i, j=1,2,6$ for orthotropic lamina are

$$
\begin{aligned}
Q_{11}^{(k)} & =\frac{E_{01}^{(k)} \bar{\varphi}^{(k)}(\bar{z})}{1-\nu_{12}^{(k)} \nu_{21}^{(k)}}, Q_{22}^{(k)}=\frac{E_{02}^{(k)} \bar{\varphi}^{(k)}(\bar{z})}{1-\nu_{12}^{(k)} \nu_{21}^{(k)}} \\
Q_{12}^{(k)} & =\nu_{21}^{(k)} Q_{11}^{(k)}=\nu_{12}^{(k)} Q_{22}^{(k)} \\
Q_{66}^{(k)} & =G_{0}^{(k)} \bar{\varphi}^{(k)}(\bar{z}) \\
& -h+(k-1) \delta \leqslant z \leqslant-h+k \delta, \bar{z}=z / h \\
k & =1,2, \ldots, N, \delta=2 h N^{-1}
\end{aligned}
$$

wherein the superscript $k$ denotes the kth layer. The quantity $E_{01}^{(k)}$ and $E_{02}^{(k)}$ are Young's modulus of the homogeneous material in the $x$ and $y$ directions for the layer $k, G_{0}^{(k)}$ are the shear modulus of the homogeneous material in the $\mathrm{x}-\mathrm{y}$ plane of the layer $k, \nu_{12}^{(k)}$ and $\nu_{21}^{(k)}$ are the Poisson's ratio for contraction in the $y$ and $x$ directions due to tension in the $x$ and $y$ directions for the 
$\mathbf{L}$
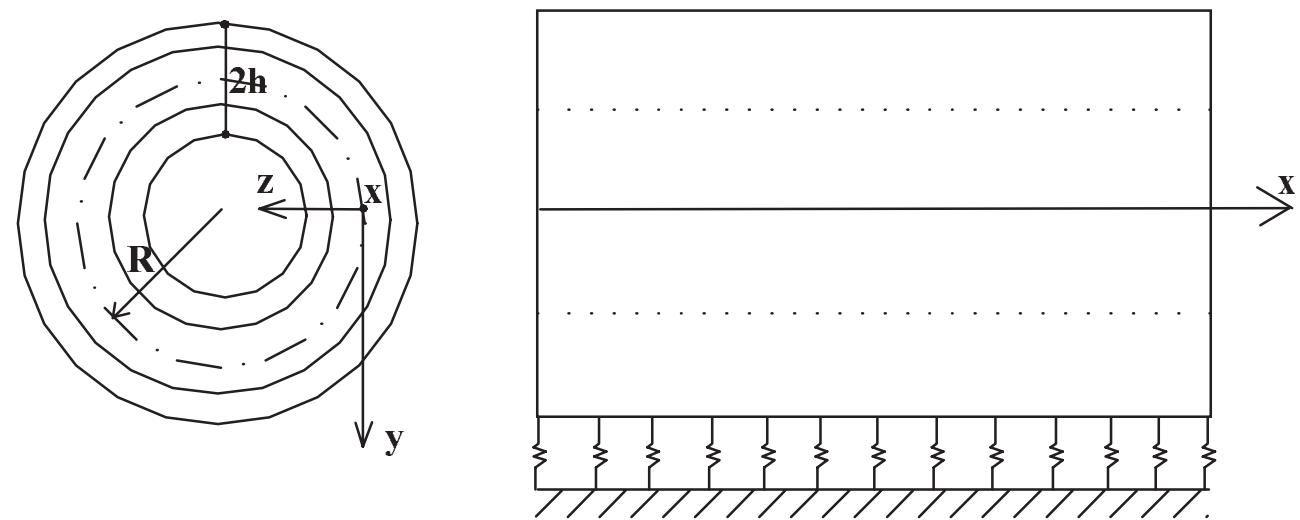

Fig. 1. Laminated cylindrical thin shell on elastic foundation.

layer $k$, respectively. There are apparently five material constants per layer; however, because of the reciprocal relations $\left(\nu_{12}^{(k)} E_{01}^{(k)}=\nu_{21}^{(k)} E_{02}^{(k)}\right)$ there are actually only four independent constants. $\bar{\varphi}^{(k)}(\bar{z})=1+\mu \varphi^{(k)}(\bar{z})$ is continuous functions expressing the variation of the Young's moduli for the layer $k$ and $\left|\bar{\varphi}^{(k)}(\bar{z})\right| \leqslant 1$. In the above expression, $\mu$ is the variation coefficient of Young's moduli and $0 \leqslant \mu<1$. $\delta$ is the equal thickness of the layers.

In the large deformation the strain compatibility equation on the reference surface is given as follows [10]:

$$
\begin{aligned}
e_{11, y y}+e_{22, x x}-2 e_{12, x y}= & \left(w_{, x y}\right)^{2}-w_{, x x} w_{, y y} \\
& -w_{, x x} / R
\end{aligned}
$$

where $e_{11}$ and $e_{22}$ are the normal strains in the curvilinear coordinate directions $x$ and $y$, respectively, whereas $e_{12}$ is the corresponding shear strain.

The force and moment resultants are defined by the following integrals $[1,24,27,33,36,39]$ :

$$
\begin{aligned}
& {\left[\left(N_{11}, N_{22}, N_{12}\right),\left(M_{11}, M_{22}, M_{12}\right)\right]} \\
& =\sum_{k=1}^{N} \int_{-h+(k-1) \delta}^{-h+k \delta}(1, z)\left(\sigma_{11}^{(k)}, \sigma_{22}^{(k)}, \sigma_{12}^{(k)}\right) d z
\end{aligned}
$$

Let $\bar{\phi}=\phi / h_{1}$ be the stress function for the stress resultants defined by

$$
\left[N_{11}, N_{22}, N_{12}\right]=\left[\phi_{, y y}, \phi_{, x x},-\phi_{, x y}\right]
$$

Considering relations (2-7) in Eq. (1) for compatibility and dynamic stability equations of laminated circular cylindrical shells resting on an elastic foundation, after some mathematical operations, one gets

$$
\begin{aligned}
& L_{1}(w)+L_{2}(\phi)-\phi_{, x x} / R=L(\phi, w) \\
& L_{3}(\phi)+L_{4}(w)+w_{, x x} / R=-0.5 L(w, w)
\end{aligned}
$$

where

$$
\begin{aligned}
L_{1}(\bullet)= & C_{3}(\bullet)_{, x x x x}+\left(C_{4}+2 C_{10}\right. \\
& \left.+C_{7}\right)(\bullet)_{, x x y y}+C_{8}(\bullet)_{, y y y y}+k_{0}(\bullet) \\
& +\rho_{1} h_{1}(\bullet)_{, t t} \\
L_{2}(\bullet)= & -C_{2}(\bullet)_{, x x x x}-\left(C_{1}-2 C_{9}\right. \\
& \left.+C_{6}\right)(\bullet)_{, x x y y}-C_{5}(\bullet)_{, y y y y} \\
L_{3}(\bullet)= & C_{16}(\bullet)_{, x x x x}+\left(C_{12}+2 C_{19}\right. \\
& \left.+C_{15}\right)(\bullet)_{, x x y y}+C_{11}(\bullet)_{, y y y y} \\
L_{4}(\bullet)= & -C_{17}(\bullet)_{, x x x x}-\left(C_{13}-2 C_{20}\right. \\
& \left.+C_{18}\right)(\bullet)_{, x x y y}-C_{14}(\bullet)_{, y y y y} \\
L(\bullet)= & (\bullet)_{, y y}(\bullet)_{, x x}+(\bullet)_{, x x}(\bullet)_{, y y} \\
& -2(\bullet)_{, x y}(\bullet)_{, x y}
\end{aligned}
$$

in which the expressions $C_{j}(j=1,2, \ldots, 20)$ are:

$$
\begin{aligned}
& C_{1}=a_{111} C_{11}+a_{121} C_{15}, \\
& C_{2}=a_{111} C_{12}+a_{121} C_{16}, \\
& C_{3}=a_{111} C_{13}+a_{121} C_{17}+a_{112}, \\
& C_{4}=a_{111} C_{15}+a_{121} C_{18}+a_{122}, \\
& C_{5}=a_{211} C_{11}+a_{221} C_{15}, \\
& C_{6}=a_{211} C_{12}+a_{221} C_{16}, \\
& C_{7}=a_{211} C_{13}+a_{221} C_{17}+a_{212}, \\
& C_{8}=a_{211} C_{14}+a_{221} C_{18}+a_{222},
\end{aligned}
$$




$$
\begin{aligned}
C_{9} & =a_{661} C_{19}, \\
C_{10} & =a_{661} C_{20}+a_{662}, \\
C_{11} & =a_{220} D, C_{12}=-a_{120} D, \\
C_{13} & =\left(a_{120} a_{211}-a_{111} a_{220}\right) D, \\
C_{14} & =\left(a_{120} a_{221}-a_{121} a_{220}\right) D, \\
C_{15} & =-a_{210} D, \\
C_{16} & =a_{110} D, \\
C_{17} & =\left(a_{210} a_{111}-a_{211} a_{110}\right) D, \\
C_{18} & =\left(a_{210} a_{121}-a_{221} a_{110}\right) D, \\
C_{19} & =1 / a_{660}, C_{20}=-a_{661} / a_{660}, \\
D & =1 /\left(a_{110} a_{220}-a_{210} a_{120}\right)
\end{aligned}
$$

Finally, the expressions for the factors $a_{i j \gamma}, i, j=$ $1,2,6$ and $\gamma=0,1,2$ are:

$$
\begin{aligned}
& a_{11 \gamma}=h^{\gamma+1} \sum_{k=1}^{N} \frac{E_{01}^{(k)} \Psi^{(k)}}{1-v_{12}^{(k)} v_{21}^{(k)}}, \\
& a_{12 \gamma}=h^{\gamma+1} \sum_{k=1}^{N} \frac{v_{21}^{(k)} E_{01}^{(k)} \Psi^{(k)}}{1-v_{12}^{(k)} v_{21}^{(k)}}, \\
& a_{22 \gamma}=h^{\gamma+1} \sum_{k=1}^{N} \frac{E_{02}^{(k)} \Psi^{(k)}}{1-v_{12}^{(k)} v_{21}^{(k)}}, \\
& a_{21 \gamma}=h^{\gamma+1} \sum_{k=1}^{N} \frac{v_{12}^{(K)} E_{02}^{(k)} \Psi^{(k)}}{1-v_{12}^{(k)} v_{21}^{(k)}}, \\
& a_{66 \gamma}=h^{\gamma+1} \sum_{k=1}^{N} G_{0}^{(k)} \Psi^{(k)}, \\
& \Psi^{(k)}=\int_{-1+2(k-1) / N}^{-1+2 k / N} \bar{z}^{\gamma} \bar{\varphi}^{(k)}(\bar{z}) d \bar{z}
\end{aligned}
$$

\section{Analytic solution of the problem}

Assuming that the cylindrical shell is simply supports at both ends, the solution of equation set (8-9) is sought in the following form [10]:

$$
w=q(t) \sin \alpha x \sin \beta y
$$

where $\alpha=m \pi / L, \beta=n / R, m$ is the half wave length in the direction of the $x$ axis, $n$ is the wave number in the direction of the $y$ axis and $q(t)$ is the time dependent amplitude. Substituting expressions (13) in the Eq. (9) and eliminating

$$
\begin{aligned}
\phi= & A_{1} \cos 2 \alpha x+A_{2} \cos 2 \beta y \\
& +A_{3} \sin \alpha x \sin \beta y
\end{aligned}
$$

where

$$
\begin{aligned}
& A_{1}=B_{1} q^{2}(t), A_{2}=B_{2} q^{2}(t), A_{3}=B_{3} q(t) \\
& B_{1}=\frac{\beta^{2}}{32 C_{16} \alpha^{2}}, B_{2} \frac{\alpha^{2}}{32 C_{11} \beta^{2}} \\
& B_{3}=\left[C_{17} \alpha^{4}\left(C_{13}-2 C_{20}+C_{18}\right) \alpha^{2} \beta^{2}\right. \\
& \left.+C_{14} \beta^{4}+\alpha^{2} / R\right] /\left[C_{16} \alpha^{4}+\right. \\
& \left.\left(C_{12}+2 C_{19}+C_{15}\right) \alpha^{2} \beta^{2}+C_{11} \beta^{4}\right]
\end{aligned}
$$

Substituting expressions (13) and (14) in Eq. (8) and applying Galerkin method in the ranges $0 \leqslant x \leqslant L$ and $0 \leqslant y \leqslant 2 \pi R$, the following nonlinear time differential equation obtained as:

$$
q_{1, \tau \tau}+\lambda_{1} q_{1}(\tau)+\lambda_{2} q_{1}^{2}(\tau)+\lambda_{3} q_{1}^{3}(\tau)=0
$$

where $q_{1}=q / h_{1}, \tau=t \omega, \omega$ is frequency parameter, $\tau$ is dimensionless parameter and the following definitions apply:

$$
\begin{aligned}
\lambda_{1}= & \frac{\Lambda_{1}+\bar{k}_{0}}{\omega^{2}}, \quad \bar{k}_{0}=\frac{k_{0}}{\rho_{1} h_{1}} \\
\lambda_{2}= & \frac{8 \beta^{2} \alpha^{2} B_{2}}{\rho_{1} \omega^{2}}, \quad \lambda_{3}=\frac{8 \alpha^{2} \beta^{2} B_{1} h_{1}}{\rho_{1} \omega^{2}} \\
\Lambda_{1}= & \frac{1}{\rho_{1} h_{1}}\left\{\left[C_{3} \alpha^{4}+\left(C_{4}+2 C_{10}+C_{7}\right) \alpha^{2} \beta^{2}\right.\right. \\
& \left.+C_{8} \beta^{4}\right]+B_{3}\left[\alpha^{2} / R-C_{2} \alpha^{4}-\left(C_{1}\right.\right. \\
& \left.\left.\left.-2 C_{9}+C_{6}\right) \alpha^{2} \beta^{2}-C_{5} \beta^{4}\right]\right\}
\end{aligned}
$$

in which

$$
k_{0}=a_{110} k_{1} / R^{2}
$$

where $k_{1}$ is a non-dimensional foundation modulus.

The expression (18) for the single layer shell made of homogeneous isotropic and orthotropic material are in the following form $[16,18]$ :

$$
\begin{aligned}
& k_{01}=E_{0} k_{1} h_{1} /\left[R^{2}\left(1-\nu^{2}\right)\right] \\
& k_{02}=E_{01} k_{1} h_{1} /\left[R^{2}\left(1-\nu_{12} \nu_{21}\right)\right]
\end{aligned}
$$

where $E_{0}, \nu$ are the Young's modulus and Poisson's ratio of the homogeneous isotropic material and $E_{01}$, $\nu_{12}, \nu_{21}$ are the Young's modulus and Poisson's ratios of the homogeneous orthotropic material, respectively.

By making the following transformation in Eq. (16), 


$$
q_{1}(\tau)=\left(A_{p} / h_{1}\right) f(\tau)
$$

below equation is obtained:

$$
\begin{aligned}
f_{, \tau \tau}(\tau) & +\lambda_{1} f(\tau)+\lambda_{2}\left(A_{p} / h_{1}\right) f^{2}(\tau) \\
& +\lambda_{3}\left(A_{p} / h_{1}\right)^{2} f^{3}(\tau)=0
\end{aligned}
$$

An approximating function will be chosen as a first approximation as [10]:

$$
f(\tau)=\cos \tau
$$

satisfying the initial conditions

$$
f(0)=1, f_{, \tau}(0)=0
$$

Substituting expression (23) in Eq.(22) and solving the resulting equation, satisfying the orthogonality condition

$$
\begin{aligned}
& \int_{0}^{\pi / 2}\left[f_{, \tau \tau}(\tau)+\lambda_{1} f(\tau)+\lambda_{2}\left(A_{p} / h_{1}\right) f^{2}(\tau)\right. \\
& \left.+\lambda_{3}\left(A_{p} / h_{1}\right)^{2} f^{3}(\tau)\right] \cos \tau d \tau=0
\end{aligned}
$$

the amplitude-frequency relation for the finite deformations of laminated non-homogeneous orthotropic cylindrical thin shells resting on elastic foundation is obtained in the following form:

$$
\frac{\omega_{N L}}{\omega_{L}}=\left[1+\frac{8}{3 \pi} \frac{A_{p}}{h_{1}} \frac{\lambda_{2}}{\lambda_{1}}+\frac{3}{4}\left(\frac{A_{p}}{h_{1}}\right)^{2} \frac{\lambda_{3}}{\lambda_{1}}\right]^{1 / 2}
$$

where

$$
\omega_{L}=\left(\Lambda_{1}+\bar{k}_{0}\right)^{1 / 2}
$$

$\omega_{L}$ is the linear frequency, $\omega_{N L}$ is the nonlinear frequency and $\omega_{N L} / \omega_{L}$ relative frequency of vibrating shell.

The dimensionless frequency parameter defined in the following form:

$$
\Delta=\omega_{L}\left[\rho_{1} R^{2} h / a_{110}\right]^{0.5}
$$

The expression (28) for a single layer shell made of homogeneous orthotropic and isotropic material are in the following form [18,31]:

$$
\Delta_{1}=\omega_{L}\left[\rho_{0} R^{2}\left(1-\nu_{12} \nu_{21}\right) / E_{01}\right]^{0.5}
$$

$$
\Delta_{2}=\omega_{L}\left[\rho_{0} R^{2}\left(1-\nu^{2}\right) / E_{0}\right]^{0.5}
$$

where $\rho_{0}$ density of the homogeneous material in a single layer shell.

The solution of Eq. (19) with initial conditions $f(0)=1, f_{, \tau}(0)=0$ have been given in [9] and the ratio of nonlinear and linear frequencies takes the form
Table 1

Comparing the results obtained in [16] (the lowest eigenfrequency $\Delta_{2}$ ) with the dimensionless frequency parameter when the effect of elastic foundation is taken into consideration $\left(m_{1}=m \pi R / L, n=2, k_{1}=0.5, h_{1} / R=0.002\right.$, $\nu=0.3)$

\begin{tabular}{lcccc}
\hline & \multicolumn{4}{c}{$\Delta_{2}=\omega_{L}\left[\rho_{0} R^{2}\left(1-\nu^{2}\right) / E_{0}\right]^{0.5}$} \\
\cline { 2 - 5 }$m_{1}$ & 1 & 2 & 3 & 4 \\
\hline Paliwal and Pandey [16] & 0.670 & 0.780 & 0.910 & 1.010 \\
Present study & 0.725 & 0.799 & 0.884 & 0.955 \\
\hline
\end{tabular}

Table 2

Comparison of frequency parameters $\Delta_{2}$ for an isotropic cylindrical shell $\left(m=1, R / h_{1}=500, L / R=6, \nu=0.3\right)$

\begin{tabular}{cllc}
\hline & \multicolumn{2}{c}{$\Delta_{2}=\omega_{L}\left[\rho_{0} R^{2}\left(1-\nu^{2}\right) / E_{0}\right]^{0.5}$} \\
\cline { 2 - 4 }$n$ & & \multicolumn{2}{c}{$\begin{array}{c}\text { Naeem and Sharma [31], } \\
\left.\text { Pumber of polynamials } N_{1}\right)\end{array}$} \\
\cline { 3 - 4 } & & 0.05976 & 0.054323 \\
3 & 0.05696 & 0.029967 & 0.027074 \\
4 & 0.027715 & 0.019339 & 0.017776 \\
5 & 0.01829 & 0.017804 & 0.017088 \\
6 & 0.01776 & 0.021587 & 0.021303 \\
7 & 0.020746 & 0.028213 & 0.028089 \\
8 & 0.028878 & 0.036524 & 0.036469 \\
9 & 0.03727 & 0.046195 & 0.046174 \\
10 & 0.04698 & 0.057105 & 0.057088 \\
\hline
\end{tabular}

$$
\begin{aligned}
& \frac{\omega_{1 N L}}{\omega_{1 L}} \\
& =\left[1+\left(\frac{A_{p}}{h_{1}}\right)^{2}\left(\frac{3 \lambda_{3}}{4 \lambda_{1}}-\frac{5}{6}\left(\frac{\lambda_{2}}{\lambda_{1}}\right)^{2}\right)\right]^{1 / 2}
\end{aligned}
$$

When $\lambda_{2}=\lambda_{3}=0, k_{1}=0$ expression (26) yields the amplitude-frequency relation for the geometric linear free vibration analysis of a laminated nonhomogeneous orthotropic cylindrical thin shell as a special case. When $\mu=0, N=1$ expression (26) yields the amplitude-frequency relation for a single layer nonhomogeneous orthotropic cylindrical thin shell resting on an elastic foundation, as another special case.

\section{Results and discussions}

To validate the analysis, for simply supported one layered orthotropic cylindrical shells, the values of relative frequency are compared with the analytical results obtained in [22] and the results obtained in [3] by using finite elements method, see in Fig. 2. For one layered isotropic cylindrical shells, a) by taking the effect of foundation into consideration, the values of dimensionless frequency parameter are compared with the analytical results obtained in Ref. [16], see Table 1, b) the values of dimensionless frequency pa- 
Table 3

Comparison of experimental and theoretical natural frequencies $(\mathrm{Hz})$ of an isotropic cylindrical shell $\left(h_{1}=2.29 \times 10^{-4}(\mathrm{~m})\right.$, $R=0.377(\mathrm{~m}), L=0.234(\mathrm{~m}), E_{0}=2 \times 10^{5}(\mathrm{MPa})$, $\left.\rho_{0}=7.8 \times 10^{3}\left(\mathrm{~kg} / \mathrm{m}^{3}\right), \nu=0.3\right)$

\begin{tabular}{cccc}
\hline$(\mathrm{m}, \mathrm{n})$ & Lakis et al. [3] & $\begin{array}{c}\text { Exper. Study } \\
\text { Lindholm et al. [37] }\end{array}$ & Present study \\
\hline$(1,5)$ & 942 & 995 & 1012 \\
$(1,6)$ & 1353 & 1430 & 1429 \\
$(1,7)$ & 1853 & 1938 & 1935 \\
$(2,3)$ & 2067 & 2070 & 2000 \\
$(2,4)$ & 1368 & 1430 & 1369 \\
$(2,5)$ & 1248 & 1313 & 1290 \\
$(2,6)$ & 1489 & 1570 & 1551 \\
$(2,7)$ & 1927 & 2050 & 1998 \\
\hline
\end{tabular}

rameter are compared with the analytical results obtained in Ref. [31], see Table 2, c) the values of natural frequency are compared with the experimental results obtained in references [23,37,39], analytical results obtained in Ref. [31] and the results obtained in [3] by using finite elements method, see Tables 3-4 and Fig. 3. The comparisons show that the present results are in accommodation with the results in literature.

Figure 2 shows, the influence of geometrical nonlinear effects on the free vibrations of a simply supported orthotropic cylindrical shell, along with corresponding results given in references [3] and [22]. The given results in [22] were obtained based on Donnell's simplified non-linear method where only lateral displacement was considered. The finite element method based on an energy formulation is used in [3]. The comparisons were carried out for non-dimensional foundation modulus $k_{1}=0$ and for the following material properties, shell parameters and mode numbers:

$$
\begin{aligned}
E_{01} & =2 \times 10^{5}(\mathrm{MPa}), E_{02}=0.05 \times E_{01}, \\
\nu_{12} & =0.2, \nu_{21}=0.05 \times \nu_{12}, \\
\rho_{0} & =7.8 \times 10^{3}\left(\mathrm{~kg} / \mathrm{m}^{3}\right), R=0.254(\mathrm{~m}), \\
L & =0.40(\mathrm{~m}), h_{1}=0.00254(\mathrm{~m}), m=1, \\
n & =4 .
\end{aligned}
$$

The values obtained in this study for the free vibration frequencies are greater than the values obtained in references [3] and [22].

In Table 1, the results obtained in this study for dimensionless frequency parameter are compared with the theoretical results obtained in [16] for the nondimensional foundation modulus of $k_{1}=0.5$. It is observed that there is an agreement with the results obtained in this study and the results in [16].

In Table 2, the values of dimensionless frequency parameter for one layered isotropic cylindrical shell for which the effect of foundation is not taken into consideration are compared with the values of dimensionless frequency parameter obtained analytically in Ref. [31]. It is observed that the results are in a well accommodation. Besides, in both of two studies, the minimum values of dimensionless frequency parameter versus the circumferential wave number $n=5$ and these values are exactly the same.

In Fig. 3, the values of natural frequencies for one layered isotropic cylindrical shell for which the effect of foundation is not taken into consideration are compared with experimental values in [23] and with analytical values obtained in [31]. There is an agreement with the results obtained in this study, analytical results obtained in [31] and experimental results obtained in Ref. [23]. Besides, although in the studies which are compared, the minimum values of natural frequencies covers the value of circumferential wave number when $n=7$, in the present study $n=6$. But in all three studies, the values of natural frequencies are approximately the same. When the results obtained in this study are compared with the theoretical results obtained in [31] and the experimental results obtained in [23], the maximum difference is $5.5 \%$ and it is covering the value of circumferential wave number $n=4$.

The values of the non-dimensional fundamental frequencies obtained from the present study are shown in Fig. 4 along with corresponding values given in references $[29,30]$, for a four layer cross-ply cylindrical shell to demonstrate the accuracy and range of applicability of the present study. All layers, for Fig. 4, are assumed to have the same geometric and material parameters and the individual layer is assumed to be orthotropic with the following material properties:

$$
\begin{aligned}
& E_{01}=25 \times E_{02}, G_{0}=0.5 \times E_{02}, \\
& \nu_{12}=0.25, \rho_{0}=1, m=1, n=4
\end{aligned}
$$

The results obtained in this study are in a well accommodation with the theoretical results obtained in [29]. However, the results obtained in [30] by using finite element are a little smaller. It is because of that, also the effect of transverse shear deformation is taken into consideration in [30]. In this study, medium length shells are used, so the values of L/R are taken into consideration in comparison which are showed in figure.

In Table 3, the values of natural frequency for one layered isotropic cylindrical shell for which the effect of foundation is not taken into consideration are compared with experimental values obtained in Ref. [37] and with the values obtained in [3] by using finite elements method. The comparison shows that the re- 
Table 4

Comparison of experimental frequency spectra of a monocoque cylindrical shell $\left(R / h_{1}=400, L / R=0.465, \rho_{0}=\right.$ $\left.8.538 \times 10^{3}\left(\mathrm{~kg} / \mathrm{m}^{3}\right), E_{0}=2.06843 \times 10^{5}(\mathrm{MPa}), \nu=0.315\right)$

\begin{tabular}{lcccccccccc}
\hline & \multicolumn{7}{c}{$\omega_{L}(\mathrm{cps})$} \\
\cline { 2 - 9 }$(\mathrm{m}, \mathrm{n})$ & $(1,3)$ & $(1,4)$ & $(1,8)$ & $(1,11)$ & $(2,5)$ & $(2,12)$ & $(3,9)$ & $(3,11)$ & $(4,9)$ & $(4,11)$ \\
\hline Experimental study Weingarten [39] & 1648 & 1266 & 590 & 765 & 2168 & 1067 & 1797 & 1560 & 2557 & 2320 \\
Present study & 1626 & 1056 & 586 & 944 & 2103 & 1252 & 1775 & 1576 & 2528 & 2143 \\
\hline
\end{tabular}



- - - Nowinski [22]

$-\leftarrow-$ Present study

$\longrightarrow$ Lakis et.al. [3]

Fig. 2. Relative frequencies versus relative amplitude $A_{p} / h_{1}$ for nonlinear vibration of an orthotropic cylindrical shell.

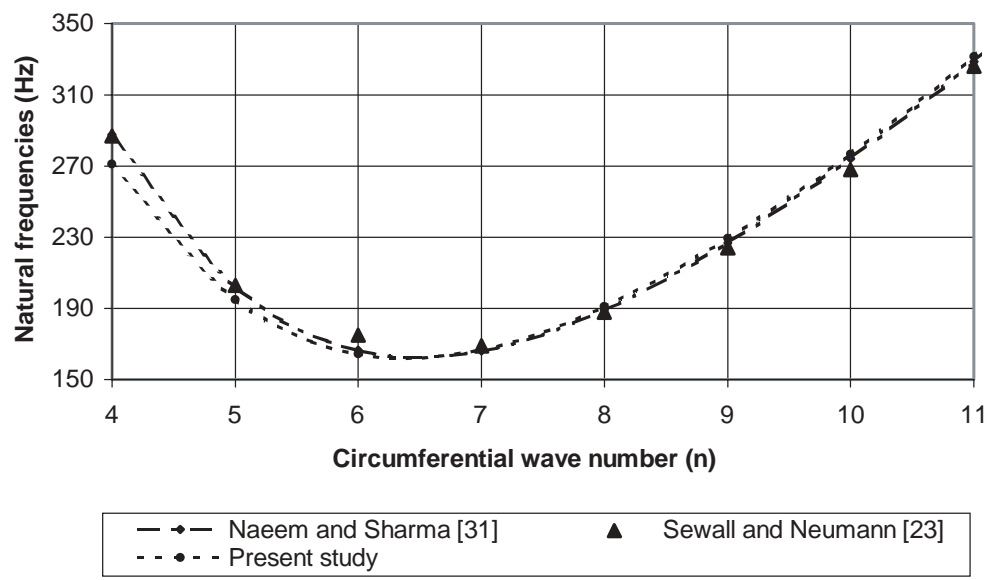

Fig. 3. Comparison of experimental and theoretical natural frequencies $(\mathrm{Hz})$ of an isotropic cylindrical shell $(h=0.000648(\mathrm{~m})$, $\left.R=0.2423(\mathrm{~m}), L=0.6096(\mathrm{~m}), m=1, k_{1}=0, \rho_{0}=2.7145 \times 10^{3}\left(\mathrm{~kg} / \mathrm{m}^{3}\right), E_{0}=68.95 \times 10^{3}(\mathrm{MPa}), \nu=0.315\right)$.

sults obtained in this study and the experimental values obtained in [37] are more approximate than the results which are obtained in [3] by using finite elements method.

In Table 4, the values of frequency spectra for one layered isotropic cylindrical shell for which the effect of foundation is not taken into consideration are compared with the values of frequency spectra obtained in [39] experimentally. It is observed that the results are in accommodation.

In the calculations presented in Table (5-10), that are done for the formulas (26)-(31) by considering the cases of cross-ply laminated orthotropic cylindrical shells up to five layers, variation function of Young's 
Table 5

Variation of the natural and relative frequencies with respect to number and ordering of layers for non-dimensional foundation modulus $k_{1}=0.01$ and variation coefficient of Young's moduli $\mu=0$ and $\mu=0.9(\mathrm{~m}=1$, $\left.n=4, h_{1}=5.08 \times 10^{-4}(\mathrm{~m}), A_{p} / h_{1}=3\right)$

\begin{tabular}{|c|c|c|c|c|c|c|c|}
\hline \multirow[b]{2}{*}{$\mathrm{N}$} & \multirow[b]{2}{*}{ Stacking of layers } & \multicolumn{3}{|c|}{$k_{1}=0, \mu=0$} & \multicolumn{3}{|c|}{$k_{1}=0.01, \mu=0$} \\
\hline & & $\bar{\omega}_{L}(\mathrm{~Hz})$ & $\omega_{N L} / \omega_{L}$ & $\omega_{1 N L} / \omega_{1 L}$ & $\bar{\omega}_{L}(\mathrm{~Hz})$ & $\omega_{N L} / \omega_{L}$ & $\omega_{1 N L} / \omega_{1 L}$ \\
\hline 1 & $\left(0^{\circ}\right)$ & 790 & 1.681 & 1.164 & 1846 & 1.155 & 1.032 \\
\hline 1 & $\left(90^{\circ}\right)$ & 618 & 2.892 & 2.858 & 1779 & 1.374 & 1.365 \\
\hline 2 & $\left(0^{\circ} / 90^{\circ}\right)\left(90^{\circ} / 0^{\circ}\right)$ & 796 & 2.033 & 1.829 & 1848 & 1.257 & 1.198 \\
\hline 3 & $\left(0^{\circ} / 90^{\circ} / 0^{\circ}\right)$ & 778 & 1.953 & 1.661 & 1841 & 1.226 & 1.146 \\
\hline 3 & $\left(90^{\circ} / 0^{\circ} / 90^{\circ}\right)$ & 803 & 2.124 & 1.989 & 1851 & 1.288 & 1.247 \\
\hline 4 & $\left(0^{\circ} / 90^{\circ} / 0^{\circ} / 90^{\circ}\right)$ & 796 & 2.033 & 1.829 & 1848 & 1.257 & 1.198 \\
\hline 4 & $\left(90^{\circ} / 0^{\circ} / 90^{\circ} / 0^{\circ}\right)$ & 796 & 2.033 & 1.829 & 1848 & 1.257 & 1.198 \\
\hline 4 & $\left(0^{\circ} / 90^{\circ} / 90^{\circ} / 0^{\circ}\right)$ & 766 & 2.092 & 1.878 & 1836 & 1.260 & 1.200 \\
\hline 4 & $\left(90^{\circ} / 0^{\circ} / 0^{\circ} / 90^{\circ}\right)$ & 824 & 1.980 & 1.785 & 1861 & 1.254 & 1.195 \\
\hline 5 & $\left(0^{\circ} / 90^{\circ} / 0^{\circ} / ..\right)$ & 785 & 1.987 & 1.732 & 1844 & 1.238 & 1.167 \\
\hline 5 & $\left(90^{\circ} / 0^{\circ} / 90^{\circ} ..\right)$ & 803 & 2.082 & 1.922 & 1851 & 1.276 & 1.227 \\
\hline $\mathrm{N}$ & & \multicolumn{3}{|c|}{$k_{1}=0, \mu=0.9$} & \multicolumn{3}{|c|}{$k_{1}=0.01, \mu=0.9$} \\
\hline 1 & $\left(0^{\circ}\right)$ & 1077 & 1.681 & 1.165 & 1986 & 1.240 & 1.051 \\
\hline 1 & $\left(90^{\circ}\right)$ & 840 & 2.897 & 2.863 & 1868 & 1.580 & 1.567 \\
\hline 2 & $\left(0^{\circ} / 90^{\circ}\right)\left(90^{\circ} / 0^{\circ}\right)$ & 1083 & 2.034 & 1.830 & 1989 & 1.389 & 1.302 \\
\hline 3 & $\left(0^{\circ} / 90^{\circ} / 0^{\circ}\right)$ & 1058 & 1.958 & 1.668 & 1976 & 1.347 & 1.230 \\
\hline 3 & $\left(90^{\circ} / 0^{\circ} / 90^{\circ}\right)$ & 1094 & 2.120 & 1.984 & 1995 & 1.432 & 1.372 \\
\hline 4 & $\left(0^{\circ} / 90^{\circ} / 0^{\circ} / 90^{\circ}\right)$ & 1083 & 2.034 & 1.823 & 1989 & 1.389 & 1.302 \\
\hline 4 & $\left(90^{\circ} / 0^{\circ} / 90^{\circ} / 0^{\circ}\right)$ & 1083 & 2.034 & 1.823 & 1989 & 1.389 & 1.302 \\
\hline 4 & $\left(0^{\circ} / 90^{\circ} / 90^{\circ} / 0^{\circ}\right)$ & 1043 & 2.098 & 1.886 & 1968 & 1.398 & 1.311 \\
\hline 4 & $\left(90^{\circ} / 0^{\circ} / 0^{\circ} / 90^{\circ}\right)$ & 1122 & 1.977 & 1.614 & 2011 & 1.381 & 1.294 \\
\hline 5 & $\left(0^{\circ} / 90^{\circ} / 0^{\circ} / ..\right)$ & 1069 & 1.988 & 1.735 & 1981 & 1.364 & 1.259 \\
\hline 5 & $\left(90^{\circ} / 0^{\circ} / 90^{\circ} ..\right)$ & 1093 & 2.083 & 1.922 & 1994 & 1.415 & 1.345 \\
\hline
\end{tabular}

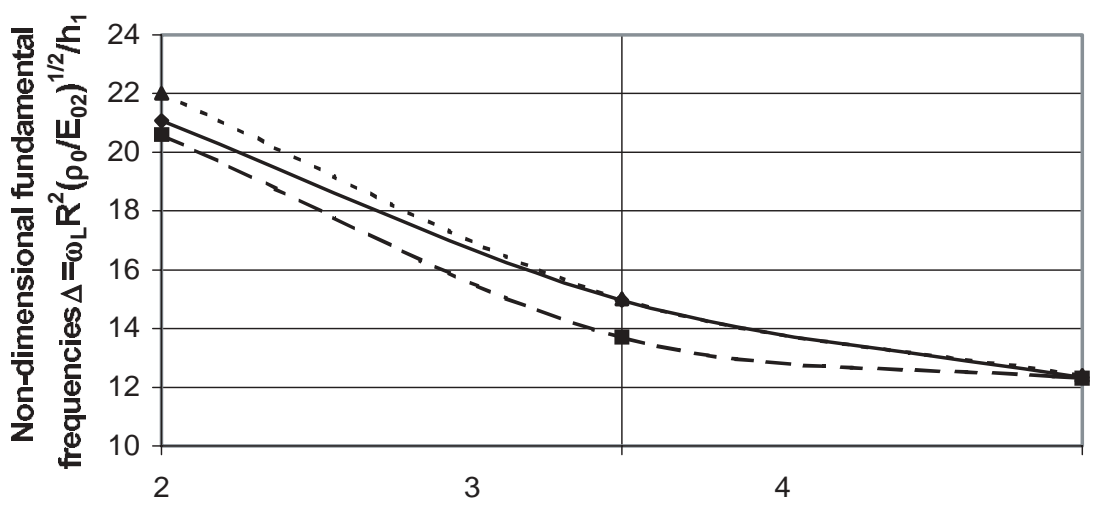

The lenght radius ratio $L / R$

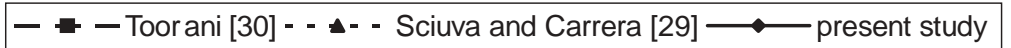

Fig. 4. Non-dimensional fundamental frequencies of simply supported cylindrical shell with symmetric cross-ply $\left(\left(\Theta / 90^{\circ} / 90^{\circ} / 0^{\circ}\right)\right.$.

moduli in layers is taken into consideration in the form $\varphi^{(k)}(\bar{z})=\exp (-0.1|\bar{z}|)$ and natural frequency is taken into consideration in the form $\bar{\omega}_{L}=\omega_{L} /(2 \pi)$ $(\mathrm{Hz})$. Furthermore, the values of variation coefficient of Young's moduli $\mu$ and non-dimensional foundation modulus $k_{1}$ are indicated in Tables (5-10). In all layers of cross-ply cylindrical shell, the material properties are same and the material properties in [2], shell pa- rameters in Ref. [39] and non-dimensional foundation modulus in Ref. [16-18,35,38] are given as:

$$
\begin{aligned}
E_{01} & =1.3237 \times 10^{5}(\mathrm{MPa}), \\
E_{02} & =1.0755 \times 10^{4}(\mathrm{MPa}), \\
G_{0} & =5.6537 \times 10^{3}(\mathrm{MPa}), \nu_{12}=0.24, \\
\nu_{21} & =0.0195, \rho_{0}=1.308 \times 10^{3}\left(\mathrm{~kg} / \mathrm{m}^{3}\right),
\end{aligned}
$$


Table 6

Variation of the relative frequency with respect to amplitude of the frequency, number and ordering of layers for $k=0.005$ and $\mu=0\left(h_{1}=2.54 \times 10^{-4}(\mathrm{~m}), m=1, n=4\right)$

\begin{tabular}{|c|c|c|c|c|c|c|c|c|}
\hline \multirow[t]{3}{*}{$A_{p} / h_{1}$} & \multicolumn{8}{|c|}{$\omega_{N L} / \omega_{L}$} \\
\hline & \multicolumn{4}{|c|}{$k_{1}=0, \mu=0$} & \multicolumn{4}{|c|}{$k_{1}=0.005, \mu=0$} \\
\hline & $\left(0^{\circ}\right)$ & 2 Layers & $\left(0^{\circ} / 90^{\circ} / 0^{\circ}\right)$ & $\left(90^{\circ} / 0^{\circ} / 90^{\circ}\right)$ & $\left(0^{\circ}\right)$ & 2 Layers & $\left(0^{\circ} / 90^{\circ} / 0^{\circ}\right)$ & $\left(90^{\circ} / 0^{\circ} / 90^{\circ}\right)$ \\
\hline 0 & 1 & 1 & 1 & 1 & 1 & 1 & 1 & 1 \\
\hline 0.5 & 1.062 & 1.044 & 1.050 & 1.039 & 1.0193 & 1.0131 & 1.0152 & 1.0131 \\
\hline 1.0 & 1.122 & 1.103 & 1.109 & 1.098 & 1.0390 & 1.0311 & 1.0338 & 1.0286 \\
\hline 1.5 & 1.182 & 1.174 & 1.176 & 1.176 & 1.0590 & 1.0538 & 1.0555 & 1.0524 \\
\hline 2.0 & 1.241 & 1.255 & 1.250 & 1.268 & 1.0793 & 1.0808 & 1.0803 & 1.0940 \\
\hline 2.5 & 1.299 & 1.345 & 1.328 & 1.371 & 1.1000 & 1.1120 & 1.1080 & 1.1170 \\
\hline 3.0 & 1.356 & 1.441 & 1.412 & 1.484 & 1.1210 & 1.1468 & 1.1382 & 1.1568 \\
\hline
\end{tabular}

Table 7

Variation of the natural frequency with respect to half axial wave number $m$, number and ordering of layers for $k_{1}=0.01, \mu=0$ and $\mu=0.9\left(n=4, h_{1}=2.54 \times 10^{-4}(\mathrm{~m}), A_{p} / h_{1}=3\right)$

\begin{tabular}{|c|c|c|c|c|c|c|c|c|}
\hline \multirow[t]{3}{*}{$\mathrm{m}$} & \multicolumn{8}{|c|}{$\bar{\omega}_{L}(\mathrm{~Hz})$} \\
\hline & \multicolumn{4}{|c|}{$k_{1}=0, \mu=0$} & \multicolumn{4}{|c|}{$k_{1}=0.01, \mu=0$} \\
\hline & $\left(0^{\circ}\right)$ & 2 Layers & $\left(0^{\circ} / 90^{\circ} / 0^{\circ}\right)$ & $\left(90^{\circ} / 0^{\circ} / 90^{\circ}\right)$ & $\left(0^{\circ}\right)$ & 2 Layers & $\left(0^{\circ} / 90^{\circ} / 0^{\circ}\right)$ & $\left(90^{\circ} / 0^{\circ} / 90^{\circ}\right)$ \\
\hline 1 & 783 & 759 & 768 & 738 & 1843 & 1833 & 1837 & 1824 \\
\hline 2 & 1575 & 1634 & 1637 & 1619 & 2295 & 2335 & 2337 & 2325 \\
\hline 3 & 2228 & 2465 & 2454 & 2461 & 2784 & 2977 & 2967 & 2974 \\
\hline 4 & 2750 & 3257 & 3224 & 3266 & 3217 & 3660 & 3630 & 3668 \\
\hline $\mathrm{m}$ & \multicolumn{4}{|c|}{$k_{1}=0, \mu=0.9$} & \multicolumn{4}{|c|}{$k_{1}=0.01, \mu=0.9$} \\
\hline 1 & 1067 & 1033 & 1046 & 1006 & 1980 & 1962 & 1969 & 1948 \\
\hline 2 & 2146 & 2226 & 2230 & 2207 & 2718 & 2782 & 2785 & 2767 \\
\hline 3 & 3036 & 3359 & 3344 & 3354 & 3464 & 3750 & 3737 & 3746 \\
\hline 4 & 3747 & 4438 & 4394 & 4450 & 4101 & 4741 & 4700 & 4752 \\
\hline
\end{tabular}

Table 8

Variation of the natural frequency with respect to the number of circumferential waves and number and ordering of layers for $k_{1}=0.005, \mu=0$ and $\mu=0.9\left(m=1, h_{1}=2.54 \times 10^{-4}(\mathrm{~m}), A_{p} / h_{1}=3\right)$

\begin{tabular}{|c|c|c|c|c|c|c|c|c|c|}
\hline \multirow[t]{3}{*}{$\mathrm{n}$} & \multicolumn{9}{|c|}{$\bar{\omega}_{L}(\mathrm{~Hz})$} \\
\hline & \multicolumn{4}{|c|}{$k_{1}=0, \mu=0$} & & \multicolumn{4}{|c|}{$k_{1}=0.005, \mu=0$} \\
\hline & $(0 \mathrm{o})$ & 2 Layers & $\left(0^{\circ} / 90^{\circ} / 0^{\circ}\right)$ & $\left(90^{\circ} / 0^{\circ} / 90^{\circ}\right)$ & & $\left(0^{\circ}\right)$ & 2 Layers & $\left(0^{\circ} / 90^{\circ} / 0^{\circ}\right)$ & $\left(90^{\circ} / 0^{\circ} / 90^{\circ}\right)$ \\
\hline 4 & 783 & 759 & 768 & 737 & 1416 & 1403 & 1408 & 1391 & \\
\hline 5 & 612 & 602 & 592 & 602 & & 1329 & 1324 & 1320 & 1324 \\
\hline 6 & 501 & 536 & 483 & 578 & & 1282 & 1296 & 1275 & 1314 \\
\hline 7 & 431 & 546 & 421 & 643 & & 1256 & 1300 & 1253 & 1344 \\
\hline 8 & 396 & 616 & 399 & 771 & & 1245 & 1331 & 1246 & 1410 \\
\hline 9 & 391 & 728 & 412 & 943 & & 1258 & 1387 & 1250 & 1510 \\
\hline 10 & 412 & 872 & 452 & 1147 & & 1250 & 1467 & 1263 & 1646 \\
\hline 11 & 454 & 1041 & 513 & 1379 & & 1264 & 1573 & 1287 & 1815 \\
\hline $\mathrm{n}$ & \multicolumn{4}{|c|}{$k_{1}=0, \mu=0.9$} & & \multicolumn{4}{|c|}{$k_{1}=0.005, \mu=0.9$} \\
\hline 4 & 1067 & 1033 & 1046 & 1006 & & 1590 & 1568 & 1576 & 1551 \\
\hline 5 & 833 & 819 & 806 & 820 & & 1444 & 1436 & 1429 & 1437 \\
\hline 6 & 682 & 729 & 657 & 786 & & 1363 & 1387 & 1350 & 1418 \\
\hline 7 & 587 & 741 & 573 & 873 & & 1318 & 1393 & 1311 & 1468 \\
\hline 8 & 539 & 835 & 543 & 1046 & & 1297 & 1445 & 1299 & 1577 \\
\hline 9 & 531 & 987 & 560 & 1278 & & 1294 & 1538 & 1306 & 1739 \\
\hline 10 & 559 & 1182 & 614 & 1553 & & 1306 & 1670 & 1330 & 1951 \\
\hline 11 & 615 & 1410 & 698 & 1868 & & 1331 & 1839 & 1371 & 2209 \\
\hline
\end{tabular}

$L / R=0.465, R=0.1016(\mathrm{~m})$

$$
\begin{aligned}
& h_{1}=2.54 \times 10^{-4}(\mathrm{~m}) \text { or } \\
& h_{1}=5.08 \times 10^{-4}(\mathrm{~m})
\end{aligned}
$$

In Table 5, by taking the number and ordering of layers, elastic foundation and the effect of nonhomogeneity into consideration, the values of natural frequency and $\omega_{N L} / \omega_{L}$ relative frequency are pre- 
Table 9

Variation of the relative frequency with respect to the number of circumferential waves and number and ordering of layers for $k_{1}=0.005$ and $\mu=0\left(m=1, h_{1}=2.54 \times 10^{-4}(\mathrm{~m}), A_{p} / h_{1}=3\right)$

\begin{tabular}{|c|c|c|c|c|c|c|c|c|}
\hline \multirow{3}{*}{$\begin{array}{c}\mu=0 \\
\mathrm{n}\end{array}$} & \multicolumn{8}{|c|}{$\omega_{N L} / \omega_{L}$} \\
\hline & \multicolumn{4}{|c|}{$k_{1}=0$} & \multicolumn{4}{|c|}{$k_{1}=0.005$} \\
\hline & $\left(0^{\circ}\right)$ & 2 Layers & $\left(0^{\circ} / 90^{\circ} / 0^{\circ}\right)$ & $\left(90^{\circ} / 0^{\circ} / 90^{\circ}\right)$ & $\left(0^{\circ}\right)$ & 2 Layers & $\left(0^{\circ} / 90^{\circ} / 0^{\circ}\right)$ & $\left(90^{\circ} / 0^{\circ} / 90^{\circ}\right)$ \\
\hline 4 & 1.356 & 1.442 & 1.412 & 1.484 & 1.121 & 1.147 & 1.138 & 1.157 \\
\hline 5 & 1.609 & 2.047 & 1.941 & 2.169 & 1.156 & 1.288 & 1.247 & 1.328 \\
\hline 6 & 1.988 & 2.899 & 2.855 & 2.959 & 1.205 & 1.506 & 1.423 & 1.581 \\
\hline 7 & 2.503 & 3.676 & 4.107 & 3.497 & 1.273 & 1.791 & 1.671 & 1.890 \\
\hline 8 & 3.096 & 4.162 & 5.449 & 3.755 & 1.368 & 2.120 & 1.987 & 2.219 \\
\hline 9 & 3.649 & 4.404 & 6.563 & 3.863 & 1.490 & 2.465 & 2.360 & 2.535 \\
\hline 10 & 4.062 & 4.513 & 7.308 & 3.907 & 1.638 & 2.801 & 2.776 & 2.816 \\
\hline 11 & 4.321 & 4.463 & 7.743 & 3.925 & 1.810 & 3.110 & 3.222 & 3.053 \\
\hline 12 & 4.465 & 4.585 & 7.981 & 3.933 & 2.000 & 3.381 & 3.682 & 3.244 \\
\hline
\end{tabular}

Table 10

Variation of the natural and relative frequencies with respect to non-dimensional foundation modulus $k$, number and ordering of layers for $\mu=0\left(m=1, n=7, h_{1}=2.54 \times 10^{-4}(\mathrm{~m}), A_{p} / h_{1}=3\right)$

\begin{tabular}{|c|c|c|c|c|c|c|c|c|}
\hline \multirow{2}{*}{$\begin{array}{c}\mu=0 \\
k_{1}\end{array}$} & \multicolumn{4}{|c|}{$\bar{\omega}_{L}(\mathrm{~Hz})$} & \multicolumn{4}{|c|}{$\omega_{N L} / \omega_{L}$} \\
\hline & $\left(0^{\circ}\right)$ & 2 Layers & $\left(0^{\circ} / 90^{\circ} / 0^{\circ}\right)$ & $\left(90^{\circ} / 0^{\circ} / 90^{\circ}\right)$ & $\left(0^{\circ}\right)$ & 2 Layers & $\left(0^{\circ} / 90^{\circ} / 0^{\circ}\right)$ & $\left(90^{\circ} / 0^{\circ} / 90^{\circ}\right)$ \\
\hline 0 & 431 & 546 & 421 & 643 & 2.5032 & 3.6764 & 4.1074 & 3.497 \\
\hline 0.005 & 1256 & 1300 & 1253 & 1344 & 1.2733 & 1.7907 & 1.6712 & 1.890 \\
\hline 0.010 & 1723 & 1755 & 1721 & 1788 & 1.1533 & 1.4866 & 1.3965 & 1.5660 \\
\hline 0.015 & 2088 & 2115 & 2086 & 2142 & 1.1067 & 1.3541 & 1.2831 & 1.4184 \\
\hline
\end{tabular}

sented. When the effect of elastic foundation isn't taken into consideration, it is observed that the effect of the variation of number and ordering of layers on the natural frequency $\omega_{N L} / \omega_{L}$ relative frequency values are very important. Besides, although the effect of nonhomogeneity on natural frequency values is very considerable, the effect of non-homogeneity on $\omega_{N L} / \omega_{L}$ relative frequency values is very little. When the effect of elastic foundation is taken into consideration, values of the natural frequency increase, however values of the relative frequency decrease and approximates to one. Consequently, the effect of non-linearity on the values of vibration frequencies decreases. Besides this, the effect of non-homogeneity and variation of layers number on the values of vibration frequency is very small. Furthermore, when the calculations done according to the formulas (26) and (31) are compared, it is observed that the values of $\omega_{N L} / \omega_{L}$ are greater than the values of $\omega_{1 N L} / \omega_{1 L}$. The formulas used for $\omega_{1 N L} / \omega_{1 L}$ relative frequency values is obtained from [9].

In Table 6, by taking various number and ordering of layers and elastic foundation into consideration, the relative frequency values are presented dependent on the variation of $A_{p} / h_{1}$. When the effect of elastic foundation isn't taken into consideration, if $A_{p} / h_{1}$ increases, the effect of geometrical non-linearity on frequency values increases. The effect of the number and ordering of layers variation on frequency values is considerable.
When the effect of elastic foundation is taken into consideration, there is no effect of variation of number and ordering of layers on the frequency values.

In Table 7, taking various number and ordering of layers, elastic foundation and non-homogeneity into consideration, the values of natural frequency for the half axial wave number are presented. When the effect of elastic foundation isn't taken into consideration $\left(k_{1}=0\right)$ and the half axial wave number increases, the values of natural frequency increases importantly and the effect of non-homogeneity, variation of number and ordering of layers is very considerable. When the effect of elastic foundation is taken into consideration $\left(k_{1}=0.01\right)$, the effect of the changes in the Young's moduli in layers on natural frequency values decrease. There is a very little effect of the variation number and ordering of layers.

By comparing Tables 5 and 7, it can be observed that, the ratio of thickness to radius $\left(h_{1} / R\right)$ variation effect on natural frequency values is considerable.

In Table 8 , by taking various number and ordering of layers, elastic foundation and non-homogeneity into consideration, natural frequency values for different circumferential wave number values are presented. When the effect of elastic foundation isn't taken into consideration, the effect of number and ordering of layers on natural frequency values in the great values of wave number is very large. For example, for the 
wave numbers $(1,11)$, in one layered $\left(0^{\circ}\right)$ ordering and three layered $\left(90^{\circ} / 0^{\circ} / 90^{\circ}\right)$ ordering shells, difference between the values of natural frequencies go up to 3 times of the first value. When the effect of elastic foundation is taken into consideration, the factors in question are not effective and the values of natural frequency are approximate with the values of one layered shell. Besides, the minimum values of natural frequency are obtained in different wave circumferential numbers by the effect of in question factors. For example, the minimum value of natural frequency is obtained for $k_{1}=0$, $\mu=0$ in the circumferential wave number $n=8$ for $\left(0^{\circ} / 90^{\circ} / 0^{\circ}\right)$ ordering shells and for $k_{1}=0, \mu=0$ in the circumferential wave number $n=6$ for $\left(90^{\circ} / 0^{\circ}\right)$ and $\left(90^{\circ} / 0^{\circ} / 90^{\circ}\right)$ ordering shells.

In Table 9, taking various number and ordering of layers and elastic foundation into consideration, $\omega_{N L} / \omega_{L}$ relative frequency values are presented for different circumferential wave number values. If the effect of elastic foundation is not taken into consideration, when circumferential wave number values increase, relative frequency values increase and for the great values of wave number, the effect of number and ordering of layers is important. For example, for $(1,12)$ wave numbers, in three layered $\left(0^{\circ} / 90^{\circ} / 0^{\circ}\right)$ and $\left(90^{\circ} / 0^{\circ} / 90^{\circ}\right)$ ordering shells, the difference between the relative frequency values is $51 \%$. When the effect of elastic foundation is taken into consideration, in small values of circumferential wave number, the factors in question are not effective and the relative frequency values are approximate with the values of one layered shells.

In Table 10, natural frequency and $\omega_{N L} / \omega_{L}$ relative frequency values for various non-dimensional foundation modulus, various number and ordering of layers are presented. When the foundation modulus increase, the effect of non-linearity on natural frequency and relative frequency values decreases. But in larger values of foundation modulus, this effect may not taken into consideration.

\section{Conclusion}

The present study considers the vibration problem of laminated non-homogeneous orthotropic cylindrical thin shells resting on elastic foundation, accounting for Karman type geometric non-linearity. Obtaining the fundamental relations employing finite deformation analysis, the equations of compatibility and dynamic stability are derived and solved simultaneously to establish an analytical relation between amplitude and frequency. The following conclusions have been drawn from the numerical analysis carried out using the general formulas obtained from the analytical study:

a) When the effect of elastic foundation is not taken into consideration, the effects of geometrical nonlinearity, non-homogeneity, number and ordering of layers are very important on frequency values.

b) When the value of foundation modulus increases, the effects of the factors in question on the frequency values decrease and these factors do not have effects on frequency values in larger values of foundation modulus.

c) When the ratio of shell thickness to radius $\left(h_{1} / R\right)$ increases, the values of natural frequency increase.

A validation of the analysis has been carried out by comparing results with those in the literature and has found to be accurate.

\section{References}

[1] A. Argento and R.A. Scott, Dynamic instability of layered anisotropic circular cylindrical shells, Part I: Theoretical development, J. Sound Vib. 162 (1993), 311-322.

[2] A.A. Khdeir, Dynamic response of cross-ply laminated circular cylindrical shells with various boundary conditions, Acta Mech. 112 (1995), 117-134.

[3] A.A. Lakis, A. Selmane and A. Toledano, Nonlinear free vibration of laminated orthotropic cylindrical shells, Int. J. Mech. Sci. 40 (1998), 27-49.

[4] A.D. Kerr, Elastic and visco-elastic foundation models, $J$. Appl. Mech. 31 (1964), 491-498.

[5] A.H. Sofiyev, The buckling of a cross-ply laminated nonhomogeneous orthotropic composite cylindrical thin shell under time dependent external pressure, Int. J. Struct. Engng. Mech. 14 (2002), 661-677.

[6] A.H. Sofiyev, The buckling of an orthotropic composite truncated conical shell with continuously varying thickness subject to a time dependent external pressure, Compos. Part B-Engng. 34 (2003), 227-233.

[7] A. Messina and K.P. Soldatos, Ritz-type dynamic analysis of cross-ply laminated circular cylinders subjected to different boundary conditions, J. Sound Vib. 227 (1999), 749-768.

[8] A.M. Zenkour and M.E. Fares, Bending, buckling and free vibration of non- homogeneous composite laminated cylindrical shell using a refined first-order theory, Compos. Part B-Engng. 32 (2001), 237-247.

[9] A.P. Bhattacharaya, Nonlinear flexural vibrations of thin shallow translational shells, J. Appl. Mech. 43 (1978), 180-182.

[10] A.S. Volmir, Stability of Elastic Systems, Nauka, Moscow, English Translation: Foreign Tech. Division, Air Force Systems Command. Wright-Patterson Air Force Base, Ohio, AD628508, 1967.

[11] B. Collet and J. Pouget, Nonlinear modulation of wave in a shallow shell on an elastic foundation, Wave Motion 34 (2001), 63-81. 
[12] B.H. Wang, J.C. Han and S.Y. Du, Dynamic fracture mechanics analysis for composite material with material nonhomogeneity in thickness direction, Acta Mech. Solida Sinica 11 (1998), 84-93.

[13] B.L. Wang, J.C. Han and S.Y. Du, Crack Problems for nonhomogeneous composite material subjected to dynamic loading, Int. J. Solid Struct. 37 (2000), 1251-1274.

[14] C. Massalas, D. Dalamanagas and G. Tzivanidis, Dynamic instability of truncated conical shells with variable modulus of elasticity under periodic compressive forces, J. Sound Vib. 79 (1981), 519-528.

[15] C.T. Loy, K.Y. Lam and C. Shu, Vibration of cylindrical shells using generalized differential quadrature, Shock Vib 4 (1997), 193-198.

[16] D.N. Paliwal and R.K. Pandey, The free vibrations of a cylindrical shell on an elastic foundation, J. Vib. Acoustics 120 (1998), 63-71.

[17] D.N. Paliwal, R.K. Pandey and T. Nath, Free vibration of circular cylindrical shell on Winkler and Pasternak foundation, Int. J. Pressure Vessels Piping 69 (1996), 79-89.

[18] D.N. Paliwal and S. Singh, Free vibrations of orthotropic cylindrical shell on elastic foundation, AIAA J 37 (1999), 11351139 .

[19] J.B. Greenberg and Y. Stavsky, Vibrations and buckling of composite orthotropic cylindrical shells with non-uniform axial loads, Compos. Part B-Engng. 29 (1998), 695-703.

[20] J.C. Chen and C.D. Babcock, Nonlinear vibrations of cylindrical shells, AIAA J 13 (1975), 868-876.

[21] J. Clastornik, M. Eisenberger, D.Z. Vancelevsky and M.A. Adin, Beams on variable Winkler elastic foundation, J. Appl. Mech. 53 (1986), 925-928.

[22] J.L. Nowinski, Nonlinear transverse vibrations of orthotropic cylindrical shells, AIAA J 1 (1963), 617-620.

[23] J.L. Sewall and E.C. Naumann, An experimental and analytical vibration study of thin cylindrical shells with and without longitudinal stiffeners, NASA TN D-4705 (1968).

[24] J.R. Vinson and R.L. Sierakowski, The behavior of structures composed of composite material, Nijhoft, Dordrecht, 1986.

[25] K.H. Ip, W.K. Chan, P.C. Tse and T.C. Lai, Vibration analyses of orthotropic thin cylindrical shells with free ends by the Rayleigh-Ritz Method, J. Sound Vib. 195 (1996), 117-135.

[26] K.K. Raju and G.V. Rao, Large amplitude asymmetric vibrations of some thin shells of revolution, J. Sound Vib. 44 (1976), $327-333$.

[27] K.M. Liew, Vibration of symmetrically laminated cantilever trapezoidal composite plates, Int. J. Mech. Sci. 34 (1992), 299-308.

[28] L.P. Khoroshun and S.Y. Kozlov , The generalized theory of plates and shells non-homogeneous in thickness direction, Naukova Dumka, Kiev (1988), (in Russian).

[29] M.D. Sciuva and E.Carrera, Elastodynamic behavior of relatively thick symmetrically laminated anisotropic circular cylindrical shells, Trans. ASME 59 (1992), 222-224.

[30] M.H. Toorani, Dynamics of the geometrically non-linear analysis of anisotropic laminated cylindrical shells, Non-Linear Mech 38 (2003), 1315-1335.

[31] M.N. Naeem and C.B. Sharma, Prediction of natural frequencies for thin circular cylindrical shells, Proc. Instn. Mech. Engng. Part C 214 (2000), 1313-1328.

[32] O. Aksogan and A.H. Sofiyev, The dynamic buckling of a cylindrical shell with variable thickness subject to a time dependent external pressure varying as a power function of time, J. Sound Vib. 254 (2002), 693-702.
[33] R.M. Jones and H.S. Morgan, Buckling and vibration of crossply laminated circular cylindrical shells, AIAA J 13 (1975), 664-671.

[34] T.Y. Ng and K.Y. Lam, Effects of elastic foundation on the dynamic stability of cylindrical shells, Int. J. Struct. Engng. Mech. 8 (1999), 193-205.

[35] T.Y. Ng and K.Y. Lam, Free vibrations analysis of rotating circular cylindrical shells on an elastic foundation, J. Vib. Acoustics 122 (2000), 85-89.

[36] T.Y. Ng, K.Y. Lam and J.N. Reddy, Dynamic stability of crossply laminated composite cylindrical shells, Int. J. Mech. Sci. 40 (1998), 805-823.

[37] U.S. Lindholm, D.D. Kana and H.N. Abramason, Breathing vibrations of circular cylindrical shell with an internal liquid, J. Aeronautical Sci. 29 (1962), 1052-1059.

[38] V.A. Bajenov, The bending of the cylindrical shells in elastic medium, Visha Shkola, Kiev (1975), (in Russian).

[39] V. Weingarten, Free vibrations of multi-layered cylindrical shells, Experimental Mech (1964), 200-205.

[40] V. Nath and R.K. Jain, Orthotropic annular shells on elastic foundations, J. Engng. Mech. 111 (1985), 1242-1256.

\section{Nomenclature}

\begin{tabular}{|c|c|}
\hline$A_{p}, A_{p} / h_{1}$ & $\begin{array}{l}\text { Amplitude and dimensionless or relative } \\
\text { amplitude of motion, respectively }\end{array}$ \\
\hline$C_{j}, a_{i j \gamma}$ & $\begin{array}{l}\text { The constants depend on properties of } \\
\text { material and shell and included by } \\
\text { Eq. (9) }\end{array}$ \\
\hline$G_{0}^{(k)}$ & $\begin{array}{l}\text { Shear moduli of the homogeneous or- } \\
\text { thotropic materials in the kth layer }\end{array}$ \\
\hline$G_{0}$ & $\begin{array}{l}\text { Shear modulus of the homogeneous ma- } \\
\text { terial in a single layer shell }\end{array}$ \\
\hline$E_{01}^{(k)}, E_{02}^{(k)}$ & $\begin{array}{l}\text { Young's moduli of the homogeneous or- } \\
\text { thotropic materials in the kth layer }\end{array}$ \\
\hline$E_{01}, E_{02}$ & $\begin{array}{l}\text { Young's moduli of the homogeneous or- } \\
\text { thotropic material in a single layer }\end{array}$ \\
\hline$E_{0}$ & $\begin{array}{l}\text { Young's modulus of the homogeneous } \\
\text { isotropic material in a single layer }\end{array}$ \\
\hline$e_{11}, e_{22}, e_{12}$ & $\begin{array}{l}\text { Axial, circumferential and shear strains } \\
\text { on the reference surface of the shell, } \\
\text { respectively }\end{array}$ \\
\hline$f(\tau)$ & Time dependent amplitude \\
\hline$h_{1}=2 h$ & Thickness of the cylindrical shell \\
\hline$k_{0}, k_{1}$ & $\begin{array}{l}\text { Foundation modulus } \\
\text { and non-dimensional foundation modu- } \\
\text { lus, respectively }\end{array}$ \\
\hline$k$ & Denotes the kth layer \\
\hline$L$ & Length of the cylindrical shell \\
\hline$m$ & Half axial wave number \\
\hline$m_{1}=m \pi R / L$ & Axial wave parameter \\
\hline$M_{11}, M_{22}, M_{12}$ & $\begin{array}{l}\text { Axial, circumferential and twisting mo- } \\
\text { ments, respectively }\end{array}$ \\
\hline$N_{11}, N_{22}, N_{12}$ & $\begin{array}{l}\text { Axial, circumferential and shear forces, } \\
\text { respectively }\end{array}$ \\
\hline$N, N_{i}$ & $\begin{array}{l}\text { Number of layers and number of poly- } \\
\text { nomials, respectively }\end{array}$ \\
\hline$n$ & Circumferential wave number \\
\hline Oxyz & $\begin{array}{l}\text { Coordinate system with the origin on the } \\
\text { reference surface of the shell }\end{array}$ \\
\hline
\end{tabular}




$\begin{array}{ll}Q_{i j}^{(k)(i, j=1,2,6)} & \text { Coefficients defined by Eq (4) } \\ q(\tau) & \text { Time dependent amplitude } \\ R & \text { Mean radius of the cylindrical shell } \\ t & \text { Time coordinate } \\ u, v, w & \text { Axial, circumferential and radial dis- } \\ & \text { placements, respectively } \\ x, y, z & \text { Rectangular coordinates (axial, circum- } \\ \alpha=m \pi / L & \text { ferential and radial, respectively) } \\ \beta=n / R & \text { Parameter } \\ \phi & \text { Parameter } \\ \varphi^{(k)}(\bar{z}) & \text { Stress function } \\ \nu_{12}^{(k)}, \nu_{21}^{(k)} & \text { Variation function of Young's moduli in } \\ & \text { the kth layer } \\ \nu_{12}, \nu_{21} & \text { Poisson's ratios of the orthotropic mate- } \\ & \text { rials in the kth layer } \\ \nu & \text { Poisson's ratios of the orthotropic mate- } \\ & \text { rials in a single layer shell } \\ & \text { Poisson's ratio of the isotropic material } \\ & \text { in a single layer shell }\end{array}$

$\lambda_{1}, \lambda_{2}, \lambda_{3}$
$\mu$
$\rho_{0}$
$\rho_{0}^{(k)}$
$\sigma_{i j}^{(k)}(i, j=1,2)$
$\tau$
$\omega$
$\omega_{L}, \bar{\omega}_{L}$,
$\omega_{N L}$
$\omega_{N L} / \omega_{L}$
$\omega_{1 N L} / \omega_{1 L}$
$\Delta, \Delta_{1}, \Delta_{2}$

Coefficients defined by Eq. (20a)

Variation coefficient of the Young's

moduli

Density of the homogeneous material in a single layer shell

Densities of the homogeneous orthotropic materials in the kth layer

Stress components in the kth layer

Dimensionless time parameter

Frequency parameter

Linear frequency and natural frequency $(\mathrm{Hz})$, respectively

Non-linear frequency of free vibrations

Relative frequency defined by Eq (26)

Relative frequency defined by Eq (31)

Dimensionless frequency parameters defined by Eqs (28-30) 

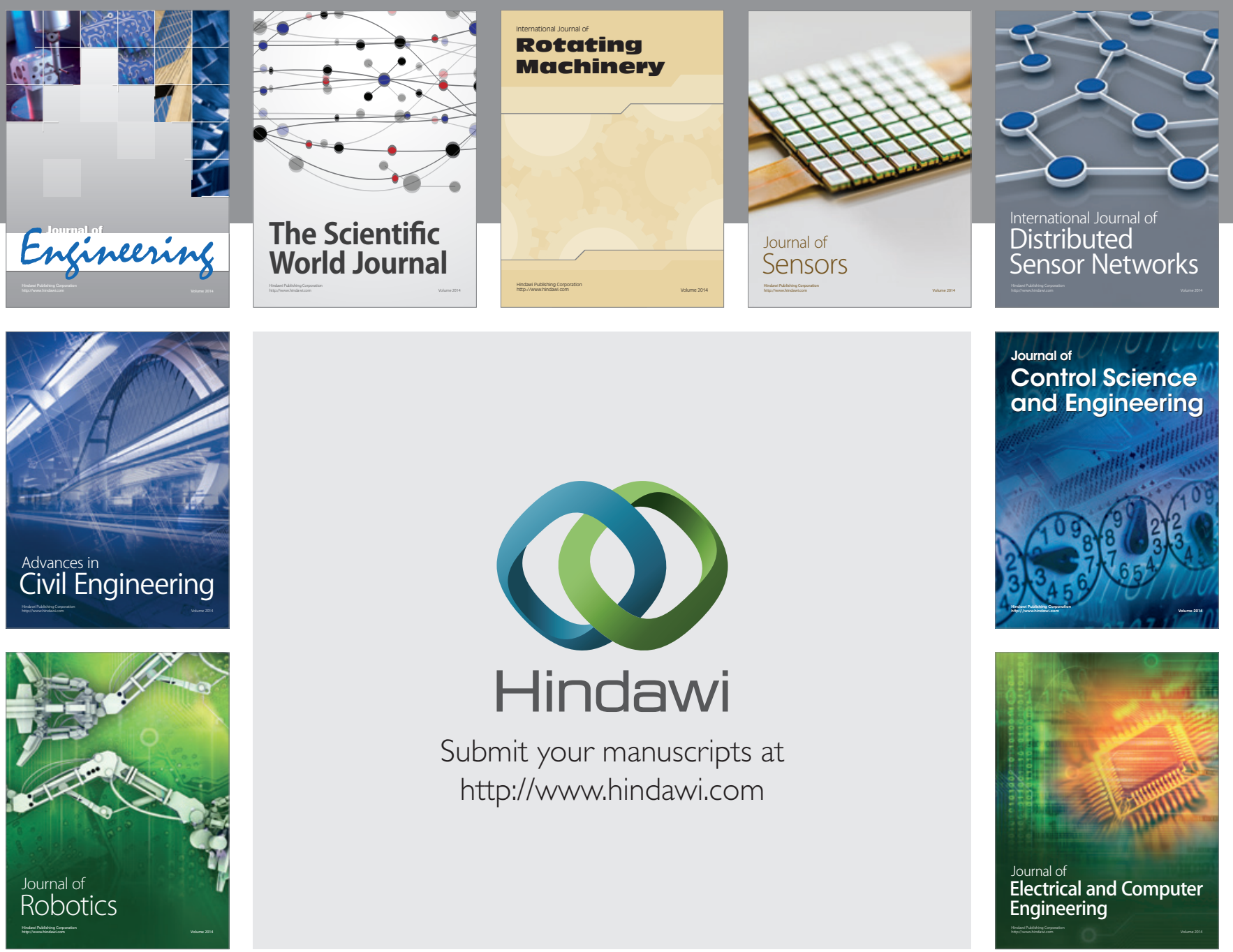

Submit your manuscripts at

http://www.hindawi.com
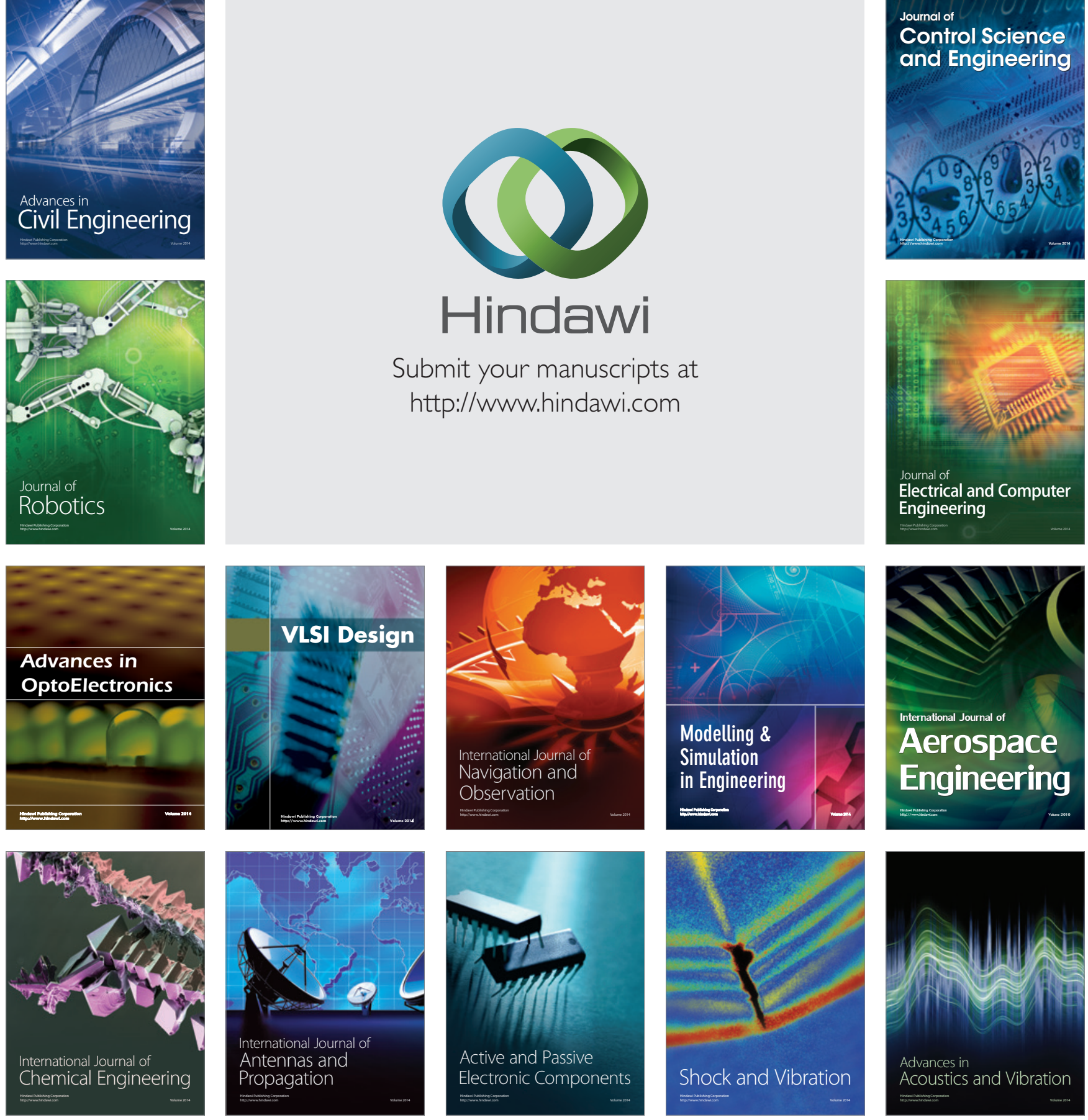